\title{
NOMES EM -DEIRA NO PORTUGUÊS
}

RESUMO: Neste texto analisa-se o funcionamento do sufixo -deira no âmbito do paradigma de formação de nomes deverbais do português europeu e brasileiro com valor agentivo e/ou instrumental. Nele se explicam os factores que estão por detrás da concorrência entre -deira e -dora em nomes instrumentais e a crescente tendência para a afectação de -eira a denominações de realidades artesanais e não teconologizadas.

PALAVRAS-CHAVE: Morfologia; léxico; semântica; sufixação.

\section{O. INTRODUÇÃO}

onstitui objectivo desta reflexão analisar o funcionamento de -deira no conjunto dos sufixos deverbais do português que formam nomes de agente e/ou de instrumento.

Partimos do pressuposto de que só o estudo da morfologia e da semântica de -deira no interior do paradigma derivacional a que pertence e que integra, entre outros, -dor/a, permite circunscrever a identidade funcional do sufixo. O valor específico de cada sufixo só pode ser identificado através dos contrastes sistemáticos e sistémicos com os outros sufixos do mesmo paradigma FUNCIO-

\footnotetext{
Universidade de Coimbra e Celga.

- Universidade de Timor-Leste.
} 
NAL, ou seja, uma vez estabelecida a rede de correlações (de contraste, de equivalência, de concorrência) intraparadigmáticas existente entre os sufixos co-funcionais.

No caso, vários são os traços morfológicos e semânticos que interrelacionam os sufixos que intervêm na formação de nomes de indivíduo/de agente e/ou de instrumento, sejam -deira/o, dor/a, -douro/a, -nte. Os nomes portadores destes sufixos podem apresentar outras significações para além da de agentividade e ou de instrumental, como a de causa, a locativa, e até a eventiva, mas vamos centrar-nos nas duas primeiras.

O trabalho que aqui se apresenta apoia -se largamente na investigação levada a cabo por Nuno Renca no âmbito da preparação da sua tese de mestrado (FLUC, 2005), e na reflexão conjunta por ambos empreendida, na qualidade de orientado-orientadora, ao longo e depois da elaboração da dissertação.

Importa dizer que nem todas as gramáticas e/ou dicionários se referem a este sufixo -deira, sendo interessante ponderar sobre quais as razões que estão na base de tal exclusão.

O sufixo deverbal -deira ocorre em "nomina actionis", como em brincadeira, mas não é nesta qualidade que aqui o analisamos. A nossa reflexão incide sobre os nomes em -deira que denotam agentes e/ou instrumentos do que o verbo de base exprime, como em lavradeira, tecedeira e debulhadeira.

\section{OSUFIXO}

O sufixo -deir- resulta da combinatória de -t-, morfema de particípio latino, com -ari-, tendo-se dado o vozemento de /t/ (tari->dari-), a metátese do $i$ por atracção da vogal $t$-nica (dari->dair-) e a assimilação da vogal nuclear do ditongo resultante (dair->deir-).

Em português a sequência -deir- configura um sufixo: /d/ pertence ao sufixo e não à base, como acontecia com o/t/latino, e por conseguinte -deira selecciona temas verbais. A lexicalização da 
sequência -deira ter-se-á dado e consolidado cedo dentro da língua. Segundo Nunes (1989, p. 370, nota 1), nas Cantigas de Santa Maria já aparece sabedeira ao lado de sabedor, então invariável. Também o nosso primeiro gramático, Fernão de Oliveira, já consigna (1536) pescadeira como derivado consagrado dentro da língua, e João de Barros [1540] (1971, p. 306) também terá mencionado poedeira (galinha) fêmea dos ovíparos que já põe ovos, ou que os põe em grande quantidade.

A questão que este sufixo coloca, para além da do lugar que ocupa no paradigma de formação de nomes de agente e/ou de instrumento deverbais, é a da relação entre -deiro e -deira, por um lado, e de -deir- com o sufixo -dor, por outro, que se destaca claramente como o sufixo mais representado na formação de nomes deverbais. Trata-se de sufixos parcial ou inteiramente concorrentes, ou a sua distribuição é complementar e obedece a que ordem de motivações?

A observação dos dicionários não se revela conclusiva, pois estes descrevem fundamentalmente a língua-padrão, dando como equivalentes denominações que efectivamente não o são. ${ }^{1}$ A consulta de fontes dialectais da segunda metade do século XX, sejam relatórios do Inquérito Linguístico Boléo, disponível no Instituto de Língua e Literatura Portuguesas da Faculdade de Letras da Universidade de Coimbra, sejam as numerosas teses de Licenciatura apresentadas nas Faculdades de Letras de Lisboa e de Coimbra nesse período, num total de 71 trabalhos, elencados em Renca (2005, p. 160-4), revela-se muito elucidativa, permitindo formular hipóteses de explicação sobre o actual valor e modo de funcionamento do sufixo -deira.

Tão ou mais elucidativas revelaram-se as fontes em linha, portuguesas e brasileiras, pois mostram uma vitalidade de -deira instrumental não comparável com a retratada pelas fontes impressas.

Sobre os critérios de selecção das fontes lexicográficas brasileiras veja-se Biderman (2002 e 2003). 
Ao longo da história, como no presente, os nomes em -dor/a cruzam-se com os nomes em -deiro/a, e tal facto não é seguramente alheio a alguma da flutuação que se verifica na distribuição deste sufixo.

Com efeito, a forma feminina -deira é uma das duas configurações de que o português antigo se serviu para substituir o não evolutivo -driz, que seria a configuração vernácula homóloga de tor-/trix. Apenas em italiano a variante feminina está não escassamente representada, pois a -tore corresponde -trice. ${ }^{2}$

Recorde-se que nos primórdios da língua os derivados em dor terão sido uniformes, só se registando a variante feminina em - $a$ no português moderno, a partir do século XVI. ${ }^{3}$ A configuração dora, perfeitamente conforme com os cânones morfológicos, mais regular e por isso facilmente aceite em vernáculo, ocupou o espaço de um virtual -driz, mas também em algumas circunstâncias -deira preenche o mesmo espaço funcional.

Assim, em lugar de -driz o português recorre a -dora ou a deira. Já Fernão de Oliveira [1536] assume que "de pescado ou pescar dizemos homem pescador e mulher pescadeira” (2000, p. 59), acrescentando que dos nomes deverbais em -or poucos têm o feminino em - $a$.

O sufixo -deira não se limita, todavia, no que concerne ao contraste de gÉnero, a servir de feminino apenas a -deiro, como em namoradeira/o, pois realiza também o feminino de -dor. Assim acontece em mondador e mondadeira ou em vindimador e vindimadeira.

2 A forma latinizante -trice surge em cantatrices e saltatrice, no século XVII (Gouveia, 2005, p. 529).

3 Segundo comunicação pessoal de Carmen Gouveia, em texto de 1548 ou de 1549 registase ainda a variante morador, referindo-se a Leonor Pinto, sendo esta a data mais recente de tal fenômeno, no corpus da autora, que tem o século XVI como termo ad quem. 
Filol. lingüíst. port., n. 9, p. 103-116, 2007.

\section{AS BASES}

O sufixo agrega-se a bases verbais de todas as classes conjugacionais, como os exemplos passar/passadeira, varrer/varredeira, urdir/urdideira o revelam. São bem mais numerosos (222 ocorrências) os derivados de temas verbais da primeira conjugação, estando a segunda e a terceira conjugações representadas com 23 e 24 ocorrências, respectivamente.

Ao nível da estrutura morfológica das bases, estas podem ser bases simples, como agenciadeira, almoçadeira, betumadeira, esmeriladeira, espadeladeira, feltradeira, sulfatadeira; bases prefixadas, assedadeira, empacotadeira, empalhadeira, enfardadeira, engarrafadeira e bases sufixadas (pranteadeira, pregueadeira, varejadeira).

No que diz respeito à estrutura argumental da base, o sufixo deira combina-se com bases mono ou pluriargumentais (cf. quadro seguinte), mas é incompatível com bases predicadoras de zero lugares (nevar/"nevadeira; granizar/"granizadeira) e com bases inacusativas (acontecer/"acontecedeira), de movimento (che-gar/"chegadeira, partir/ "partideira, sair/"saideira) ou de mudança de estado (desmaiar/ *desmaiadeira, falecer/*falecedeira; nascer/"nascedeira, murchar/ *murchadeira).

\begin{tabular}{|l|c|}
\hline \multicolumn{1}{|c|}{ Bases verbais } & Derivados em -deira \\
\hline Monoargumentais & almoçadeira, bailadeira \\
\hline Pluriargumentais & cantadeira, cortadeira, guardadeira, lavradeira \\
\hline
\end{tabular}

No que respeita à natureza eventivo-temática dos predicadores de base, os estativos não são seleccionados por -deir-. Assim, não se encontram representadas unidades formadas a partir de verbos estativos existenciais (existir/"existideira), experienciais (gostar/ *gostadeira, sofrer/"sofredeira) ou locativos (morar"moradeira, habitar/ *habitadeira). 
As restrições de selecção verificadas explicam-se provavelmente por contraste com as propriedades dos demais sufixos nominalizadores deverbais (cf. Rodrigues, 2007).

\section{OS NOMES}

Tecidas estas considerações, observemos então os nomes deverbais sufixados em -deira.

(i) o sufixo -deira funciona essencialmente como formante de nomes de instrumentos (batedeira, caçadeira, calçadeira, escumadeira, frigideira, pregadeira, roçadeira (fouce), torradeira), tendo-se de certo modo especializado neste valor, em paralelo aliás como o valor mais sistemático associado a -dora, em calculadora, debulhadora, empilhadora, escavadora, metralhadora, misturadora, picadora $(1,2,3)$, trituradora.

Antes de avançarmos para a análise dos dados empíricos, impõe-se uma reflexão sucinta sobre a metalinguagem (nomes "agentivos", nome instrumentais) aqui usada. Booij (1986, p. 507), ciente de que o papel temático absorvido pelos nomes deverbais tradicionalmente chamados "nomina agentis" nem sempre é o de agentivo, propõe a designação de nomes-sujeito, também ela não insusceptível de ambiguidade, pois remete para uma função sintáctica tão canónica e fundamental, como a de sujeito. Ora, não sendo esta a que é desempenhada por -deira, continuamos a preferir a designação de "agentivo" ou de nomes de agente. ${ }^{4}$

No conjunto dos nomes de agente ou de instrumento em deira coligidos por Renca (2005), a maior parte são denotadores de instrumentos, o que não acontece com os nomes em -dor/a.

\footnotetext{
4 Alguns autores distinguem os "nomes de agente", que se definem pelo traço "que tem a função de", pela existência de uma capacidade dirigida para o exercício/cumprimento de uma função (estudante, mergulhador), dos nomes de objectos instrumentais, marcados pelo traço "que tem a funcionalidade de" (debulhador/a). Mas esta dicotomia não se compadece com nomes do tipo grelhador, que denotam indivíduo e aparelho/utensílio, ou com bobinadora, engarrafador (que ou aquele que V; utensílio para V).
} 
Filol. lingüíst. port., n. 9, p. 103-116, 2007.

-dor: AG (72\%), AG/INSTR (17\%), INSTR (10\%), LOC (1\%)

-dora: INSTR (66\%: 25), AG (32\%: 7)

Nomes em -deira (Renca, 2005)

\begin{tabular}{|l|l|}
\hline Instrumento (debulhadeira) & $175: 61,4 \%$ \\
\hline Agente (lavradeira) & $75: 26.3 \%$ \\
\hline $\mathrm{Ag} /$ Instr (engarrafadeira) & $35: 12.3 \%$ \\
\hline & $285: 100 \%$ \\
\hline
\end{tabular}

Um nome que admite leitura agentiva e instrumental, como engarrafadeira, é descrito como "1. mulher que engarrafa. 2. máquina que engarrafa" (DLP).

Diga-se, aliás, entre parêntesis, que no caso de -dor/-dora (vendedor/a, morador/a, pensador/a, empreendedor/a) o feminino apresenta uma menor variação semântica relativamente ao masculino, muitas vezes denominando a fêmea e o macho respectivos.

Já em relação a -deiro (54 de todos os tipos no DLP) e -deira (269 DLP), a variação e a distância semântica entre o que é denotado pelo masculino e pelo feminino é mais acentuada (agasalhadeiro, andadeiro, arranjadeiro, benzedeiro, casadeiro, cevadeiro, fiadeiro, mondadeiro, rezadeiro, traduzideiro, trazedeiro, vindimadeiro, vinhadeiro ), pois o contraste de gênero lexical não é correlativo do contraste macho/fêmea, o que aponta para uma especialização semântica de deira e de -deiro.

Para começar, muitos dos nomes em -deiro são locativos (apeadeiro, atascadeiro, atoladeiro, desfiladeiro, lavadeiro, paradeiro, picadeiro, resvaladeiro). E, como vimos, também muitos dos nomes em -deira são instrumentais.

(ii) casos do tipo debulhadora ${ }^{5} /$ debulhadeira ou espremedor, espremedora (www.linguateca.pt, CETEM.Público, em 4/9/2006), espremedeira (ausente do Dicionário da Academia; (www.linguateca.pt,

5 Exemplos de ocorrência de debulhadora extraídos do CETEM.público em 4/9/2006:

.Ext 142601 (soc, 95a): Nos últimos dias de Maio, tal como faz há várias décadas, Pedro Seixas dirigiu todas as operações, mandou vir uma enorme debulhadora da zona de Mafra, ceifou a seara e ensilou a palha e o trigo. 
CETEM.Público, em 4/9/2006), só aparentemente configuram uma situação de concorrência, pois ou as funcionalidades específicas dos objectos denominados pelos nomes em -deira são muitas vezes diferentes das dos instrumentos denominados pelos nomes em -dor/a, ou o âmbito geopragmático da sua utilização é diverso.

A denominação debulhadeira (ausente no CETEM.Público, em 4/9/2006) é a que mais se ouve a nível popular em várias regiões do país para debulhadora. E, a fazer fé nas fontes em linha disponíveis no vasto universo brasileiro, é uma denominação amplamente representada no Brasil. Numa pesquisa efectuada no motor de busca safari em 12 de setembro de 2006, foram encontrados:

- 24 registos de espremedeira (de limões, de suco, de batatas), ${ }^{6} \mathrm{e}$

- 397 registos de debulhadeira (manual, mas também já tecnológica): debulhadeira de amendoim (www.furg.br), de feijão (www.

.Ext 241930 (clt, 97a): Muitas das peças vieram da Companhia Agrícola de Penha Garcia, outras da casa Lopes Cardoso, de Medelim, como por exemplo uma máquina a vapor que permite transmitir energia à debulhadora.

.Ext 729006 (soc, 94b): Nesta localidade alentejana uma casa foi destruída, tal como uma vacaria, dois tractores e uma debulhadora.

.Ext 797816 (clt, 96b): Por isso, na segunda sala, está uma máquina a vapor que aparece no Alentejo em 1870, encarregue de puxar a pesada e enorme debulhadora que está ao ladoo conjunto parece mais um combóio e • difícil imaginar o impacto da sua presença na paisagem alentejana.

.Ext 1090802 (clt, 91b): E pode-se ver uma debulhadora dentro de um tractor no meio daqueles penedos a fazer o seu trabalho.

.Ext 1175038 (clt, 95b): A partir do momento em que se introduz a maquinaria nos campos, torna-se difícil cantar por cima de uma debulhadora mecânica.

.Ext 1196707 (soc, 95b): Do campo de trigo onde fala com o PÚBLICO, com a ceifeira debulhadora a avançar ao lado, Custódio Gingão aponta para terrenos "cobertos de mato" que cortam o horizonte.

.Ext 1197163 (pol, 92a): Ao fundo de um caminho lamacento, a cabana de Jafar está vazia, enquanto a debulhadora enferruja e se cobre de teias.

.Ext 1233694 (nd, 95b): Naquele hangar, cabia um tractor, uma debulhadora, mais um quintal de batatas ou de milho.

6 Cf. as páginas da internet: <http://www.geocities.yahoo.com.br $>$, <http:// www.revistagloborural.globo.com $>$. Foram naturalmente desconsiderados todos os casos em que espremedeira é equivalente a "diarreia". 
centraldogdo.com.br), de espigas de milho (www.dns3.sefa3.rr.gov.br), de milho verde, de milho (e dragas), de milho expert, $100 \%$ inox e blindada, banca reforçada e com rodízios (www.dmm.com.br); debuladeira possante, tocada por força motriz (www.propesp. nepg.br); na debulhadeira precisa de 6 a 7 pessoas, porque se ela trabalhar sem muito milho, joga muito fora (www.biblioteca.unesp.br).

Curiosamente, debulhadeira é dado como equivalente a debulhadora em ambientes dialectais (cf. Renca, 2005, p. 141), tais como na variante dialectal alentejana (J. A. Pombinho Júnior, 1935, p. 158), em Sátão, concelho da Beira Interior portuguesa (Carvalho, 1970, p. 518) e na Ilha do Faial (Baptista, 1970, p. 565).

Em relação a espremedor ${ }^{7}$ e espremedora (este ausente do CETEM.Público, em 4/9/2006, tal como espremedeira), podemos invocar o seguinte extracto do CETEM/Público, de 4/9/2006:

Ext 658146 (soc, 92b): O espremedor de citrinos é mais primitivo que um electrodoméstico, mas é mais bonito, além de simpaticamente anacrónico .

Todavia, noutro extracto, em que se fala da produção e/ou requalifação de objectos artísticos, ou seja, de arte, já espremedor pode denominar um utensílio manual ou mecânico.

Ext 1173221 (clt, 94b): Pedro Portugal pôs uma almofada na parede, chama-lhe "almofada para dormir em pé" e subintitula-a "produto branco"; Rosa Almeida fez um "cesto" com rolos e pregos de cabeleireira; Rui Toscano chama a um muro de "tijolos" (rádiosgravadores portáteis conotados com a audição de "heavy metal"), "Bricks are heavy"; Francisco Ferro cruza um vulgar passador no elegante espremedor de citrinos de Philip Starck que, como se sabe, funciona mal e chama-lhe "Presse Citron Fonctionel".

Ext 658146 (soc, 92b): O espremedor de citrinos é mais primitivo que um electrodoméstico, mas é mais bonito, além de simpaticamente anacrónico. 
RIO-TORTO, Graça e RENCA, Nuno. Nomes em -deira no português

O facto de o sufixo -deira estar preferencialmente ligado à denominação de ofícios, dispositivos e instrumentos de carácter artesanal, essencialmente agrícola e não tecnologizado, explica a especialização semântico-referencial que afecta os nomes em que ocorre e o carácter dialectal de algumas das denominações em que entra.

O quadro seguinte ilustra esta realidade.

\begin{tabular}{|c|c|}
\hline 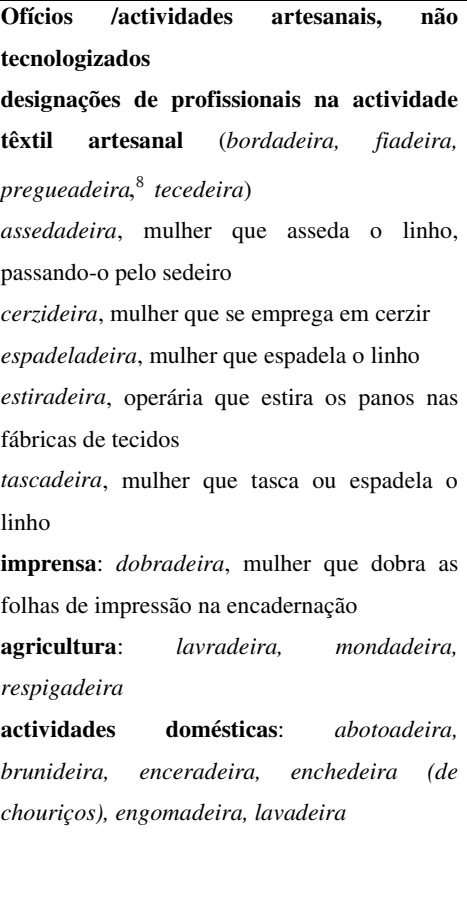 & $\begin{array}{l}\text { Instrumentos: } \\
\text { arrasadeira, pau cilíndrico para arrasar } \\
\text { medidas } \\
\text { calcadeira, pau com que os moleiros calcam a } \\
\text { farinha nos sacos } \\
\text { encarretadeira, maquinismo das fábricas de } \\
\text { fiação } \\
\text { empacotadeira, máquina agrícola que serve } \\
\text { para enfeixar e comprimir palha ou feno } \\
\text { enfardadeira, máquina agrícola que serve para } \\
\text { enfardar palha ou feno } \\
\text { enroladeira, mecanismo que enrola os tecidos } \\
\text { nas fábricas de tecelagem } \\
\text { lançadeira, peça do tear, em forma de naveta, } \\
\text { com um pequeno cilindro ao meio, em que se } \\
\text { enleia o fio que os tecelões ou tecedeiras fazem } \\
\text { passar pela urdidura } \\
\text { retorcedeira, máquina de torcer dois ou mais } \\
\text { fios } \\
\text { zinideira, pedaço de verga espalmada, preso } \\
\text { por um fio a um pau que os rapazes agitam } \\
\text { para o fazerem zunir }\end{array}$ \\
\hline
\end{tabular}

Ext 1066145 (opi, 97b): Mas enquanto Costa faz militantemente de conta que está pacificado e gratificado com o seu destino (apenas por gostar de ser ministro, seja em que pasta fôr?), Starck finge vomitar furiosamente sobre o seu passado de criador de formas sofisticadas (quem não gostaria de ter uma mesa, uma cadeira ou um simples espremedor de limões assinados por ele?).

8 Com a industrialização da actividade, bordadeira, fiadeira e pregueadeira passam também a designar aparelhos. 
A distribuição e evolução de alguns destes nomes mostra, pois, o funcionamento da escala de abstracção proposta por Booij (1986): agente pessoal $>$ agente impessoal $>$ instrumento; e por Dressler (1986): agente $>$ instrumento $>$ locativo/origem.

(iii) em relação aos produtos em que coexistem as três configurações, como os registrados em (1), coloca-se a hipótese de o produto em -deira ser ou não equivalente ao derivado em -dor, na forma feminina, ou ser deste concorrente.

(1) lavrador, lavradora (esposa), lavradeira (designação de trabalho)

vendedor, vendedora $=$ vendedeira

conversador, conversadora vs conversadeira (pop.)

trabalhador, trabalhadora vs trabalhadeira (predicativo)

O Dicionário da Academia coloca no mesmo pé de igualdade lavradora e lavradeira, e vendedora e vendedeira. Ora, a análise de outras fontes lexicográficas e das fontes dialectais compulsadas permite constatar que, nestes casos, o nome em -deira

- ora representa a configuração mais antiga e dialectal do masculino em -dor, como em lavradeira e em vendedeira,

- ora apresenta um valor caracterizante e não classificatório, como em trabalhadeira e conversadeira, identificando alguém do sexo feminino que revela tendência para determinado comportamento, no caso trabalhar ou conversar muito.

Em abono desta hipótese carreia-se o facto de os nomes actualmente usados como classificadores e que, nessa qualidade, denotam classes profissionais, apresentarem no presente uma forma masculina e outra feminina (trabalhador/a; varredor/a, vendedor/a), refectindo assim a distribuição mais equitativa nas relações laborais entre homens e mulheres. As mulheres-trabalhadoras representam um segmento do mercado quase idêntico ao dos homens, havendo hoje em dia também mais mulheres a exercer a função de vendedora.

Os antigos nomes outrora classificadores trabalhadeira e vendedeira foram, pois, postergados pelos mais padronizados vendedora e trabalhadora, pelo que aqueles passaram a ser marcados 
como dialectais e mais antigos (vendedeira) e/ou como caracterizantes (muito/pouco trabalhadeira, conversadeira). Anote-se que trabalhadora também pode acumular valor caracterizante.

Este é claramente um domínio em que a realidade sociológica se reflecte na reordenação e na mudança sufixal, motivando-a e determinando-a. E é também um sub-sector da formação de palavras em que, fruto da coexistência de diversos afixos com funcionalidades próximas e que se intersectam em alguns casos, não é linear simplificar as coisas e dizer que -dora representa o feminino gramatical de -dor e -deira o feminino gramatical de -deiro. ${ }^{9}$ A descrição da estrutura lexical dos derivados portadores destes sufixos acusa uma notória influência dos aspectos e dos papéis sociais e funcionais atribuídos aos indivíduos por eles denominados. A relação língua e cultura, tantas vezes ou secundarizada, ou sobrevalorizada, tem aqui lugar de eleição, que não pode ser ignorado ou contornado.

Assim, lavadeiro denota "cesto de medir sardinha" (DLP), mas não *homem que lava roupa por ofício. Já lavadeira denomina "1. mulher que lava roupa (DLP), 2. máquina para lavagem de lãs”.

Por último, e para quem ensina língua portuguesa, importa assinalar que, sob o ponto de vista funcional, se verifica uma clara assimetria de recursos morfológicos, em que vários afixos ora cumprem a mesma função semântica, sendo cofuncionais e concorrenciais, ora se afirmam como portadores de valores diferenciados, reflectindo, de forma eloquente, nesta dinâmica de correlações, o período de transformação que o sistema derivacional vivencia. Por isso a análise do sistema sufixal deve ser levada a cabo em rede, em interface, tendo em conta todas as variáveis linguísticas e extralinguísticas em jogo.

9 No português europeu atesta-se batedor da polícia, mas não (ainda) *batedora da polícia, e no domínio dos instrumentais temos batedeira, varinha batedora, "batedora. 
Filol. lingüíst. port., n. 9, p. 103-116, 2007.

\section{BIBLIOGRAFIA}

BARROS, J. de (1971) [1540] Gramática da língua portuguesa, cartinha, gramática, diálogo em louvor da nossa linguagem e diálogo da viciosa vergonha. (ed) Maria Leonor Carvalhão Busecu. Lisboa: Publicações da Faculdade de Letras de Lisboa.

BECHARA, E. (2004) Moderna gramática portuguesa. 37. ed. rev. e ampl. Rio de Janeiro: Lucerna.

BIDERMAN, M. T. C. (2003) O Dicionário da Língua Portuguesa Contemporânea da Academia das Ciências de Lisboa: apreciação crítica. Actas do XIX Encontro Nacional da Associação Portuguesa de Linguística. Lisboa: APL, p. 337-49.

(2002) Análise de dois dicionários gerais do Português Brasileiro contemporâneo: o Aurélio e o Houaiss. Filologia e Lingüística Portuguesa, 5, p. 85-116.

BOOIJ, G. 2005) The grammar of words. Oxford: Oxford University Press.

. (1986) Form and meaning in morphology: the case of Dutch agent nouns. Linguistics, 24, p. 503-18.

DRESSLER, W. (1986) Explanation in natural morphology, illustrated with comparative agentnoun formation. Linguistics, 24, p. 519-48.

GOUVEIA, C. (2005) A categoria gramatical de género do português antigo ao português actual. In: RIO-TORTO, G. et al. Estudos em homenagem ao Professor Doutor Mário Vilela. Porto: Faculdade de Letras da Universidade do Porto, p. 527-44.

NUNES, J. J. (1989) Compêndio de gramática histórica portuguesa. 9. ed. Lisboa: Clássica Editora.

OLIVEIRA, F. de (2000) [1536] Gramática da linguagem portuguesa. Edição crítica, semidiplomática e anastática por Amadeu Torres e Carlos Assunção. Lisboa: Academia das Ciências de Lisboa.

RENCA, N. M. L. N. (2006) Derivação nominal em -dor/a e em deiro/a no português europeu contemporâneo. Dissertação (Mestrado em Linguística Portuguesa) - Universidade de Coimbra.

RIO-TORTO, G. (1998) Morfologia derivacional: teoria e aplicação ao português. Porto: Porto Editora, Colecção "Linguiística" 12.

RODRIGUES, A. (2007) Formação de substantivos deverbais sufixados em português. Dissertação (Doutoramento em Linguística Portuguesa) - Universidade de Coimbra.

\section{Fontes}

Em linha: www.linguateca.pt: CETEM.Público impressas e electrónicas:

BAPTISTA, M. de F. F. (1970) Ilha do Faial, Contribuição para o estudo da sua linguagem, etnografia e folclore. Dissertação (Mestrado em Licenciatura) - Universidade de Coimbra (inédita).

CARVALHO, M. A. da C. A. de (1970) Sátão: Estudo da linguagem, etnografia e folclore das suas freguesias. Dissertação (Mestrado em Licenciatura) - Universidade de Coimbra (inédita). COSTA, A.; SAMPAIO e MELO (1996) Dicionário da língua portuguesa. 8. ed. Porto: Porto Editora, Priberam Informática, em suporte informático. [DLP] 
RIO-TORTO, Graça e RENCA, Nuno. Nomes em -deira no português

MALACA CASTELEIRO, J. (coord.). (2001) Dicionário da Língua Portuguesa Contemporânea da Academia das Ciências de Lisboa (2001). Lisboa: Academia das Ciências de Lisboa e Editorial Verbo, 2v.

HOUAISS, A.; VILlAR, M. de S. (2001) Dicionário Houaiss da Língua Portuguesa. Rio de Janeiro: Objetiva. Versão electrónica (CD-ROM), Dicionário Eletrónico Houaiss da Língua Portuguesa. Rio de Janeiro, Instituto António Houaiss: Objetiva.

POMBINHO Jr., J. A. (1935) Vocabulário alentejano (subsídios para o léxico português. Revista Lusitana, XXXIII, p. 94-176.

ABSTRACT: This text analyses the semantic functions of the suffix -deira within agentive and/or instrumental deverbal nouns of European and Brazilian Portuguese. We intend to highlight the historical and socio-cultural motivations which explain the current coexistence of -deira and dora in instrumental nouns, and the increase in use of -eira in denominations of artisanal, archaic and non-technical activities or instruments.

KEYWORDS: Morphology; lexicon; semantics; suffixation; Portuguese language. 